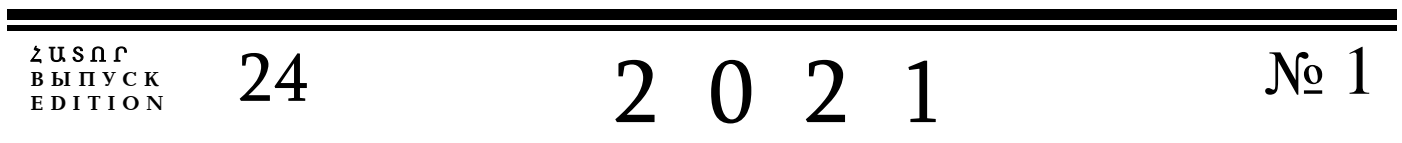

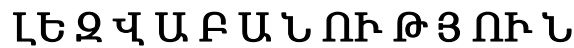

Я 3 Ы К О 3 Н АН И Е

L I N G U I S T I C S

ZST' 801.7

DOI: 10.52971/18294316-2021.1-119

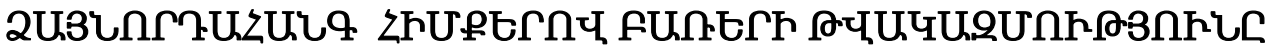 ZKし ZUBEREしกhU
}

\section{Lhһhp Fuuzuunpjuis}

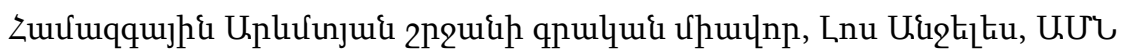

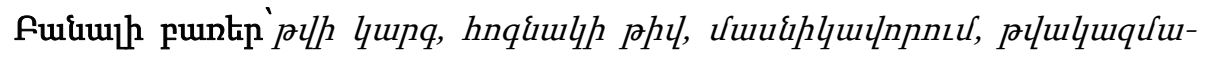

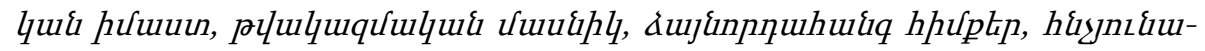

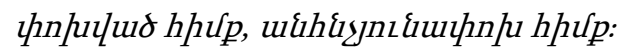

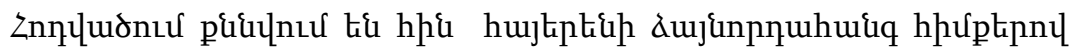

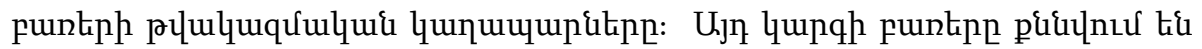

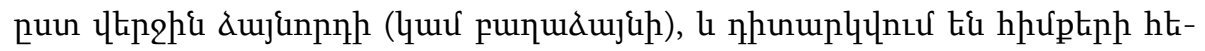

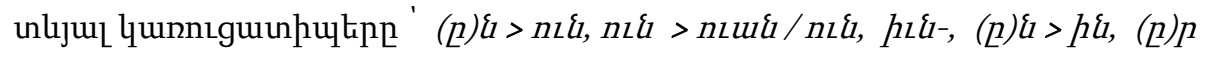

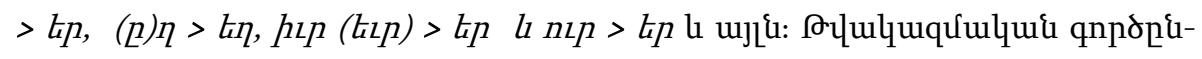

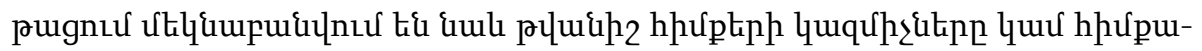

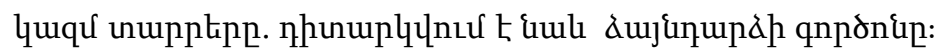

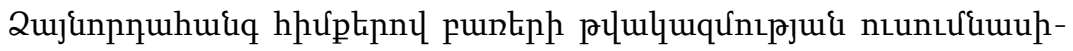

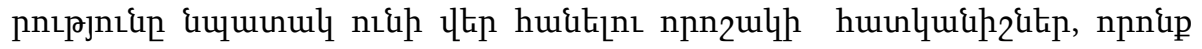

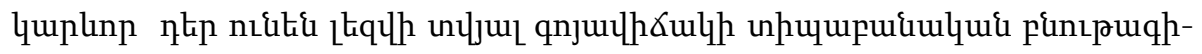
nn nnn 2 tent hungnư:

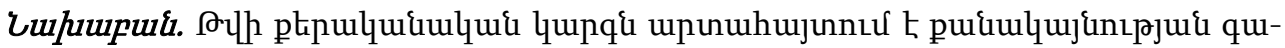

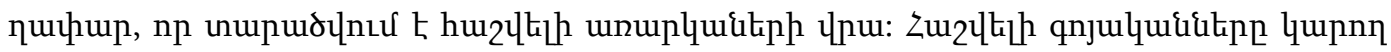

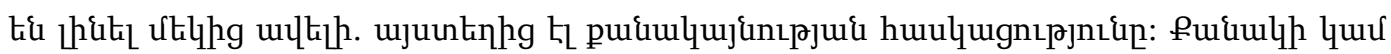

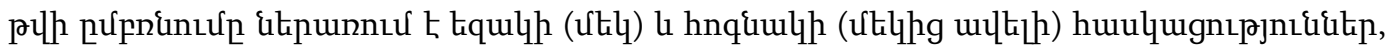

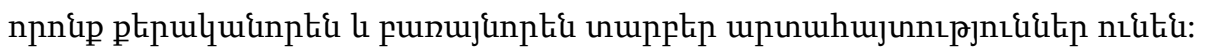

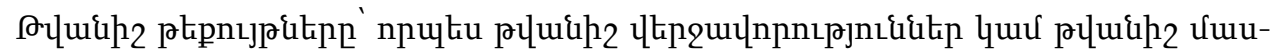

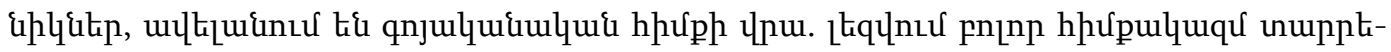

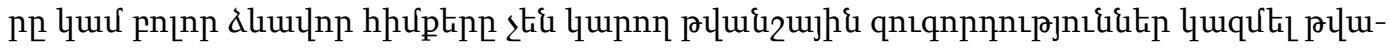




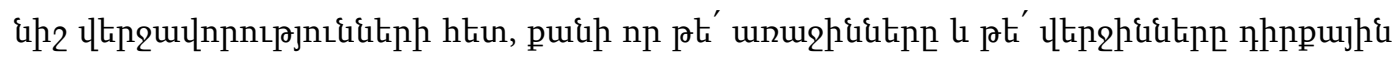

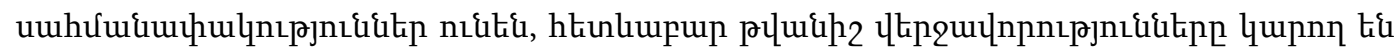

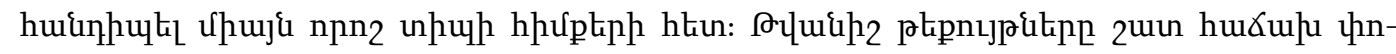

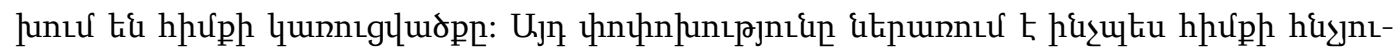

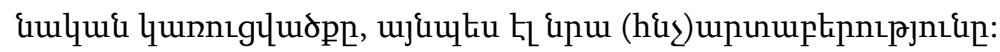

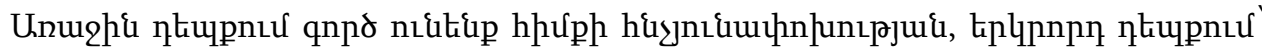

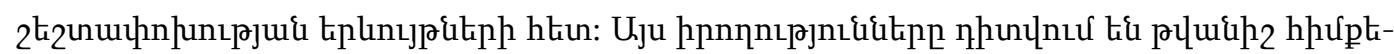

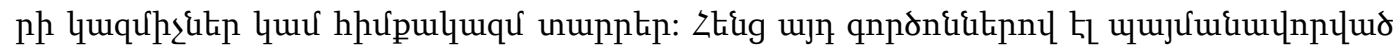

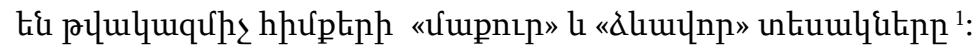

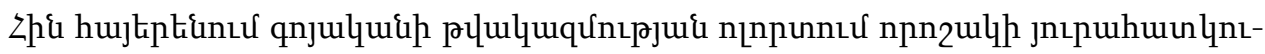

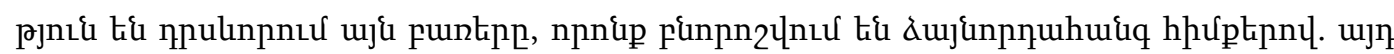

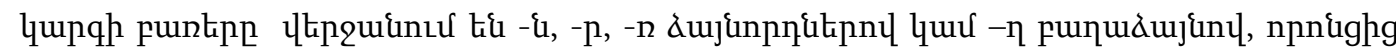

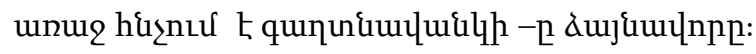

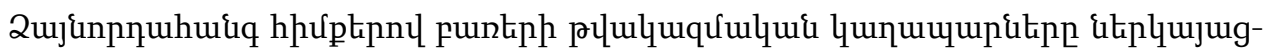

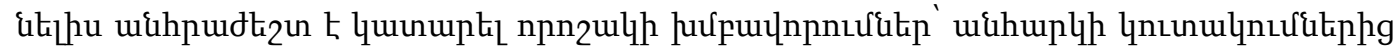

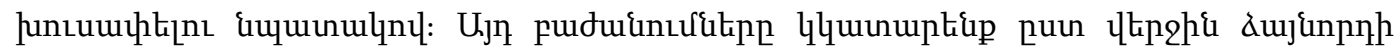

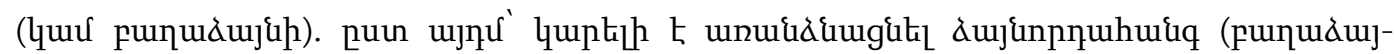

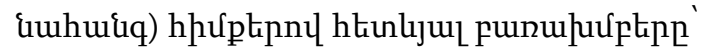

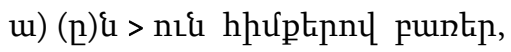

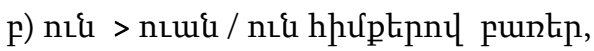

q) hıqu- hpupptinnl punten,

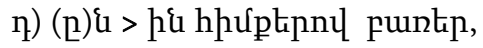

Ł) () $n>$ tip hpufptinnl punten,

q) (n) $\eta>\operatorname{tin}$ hhúptinnl puntip,

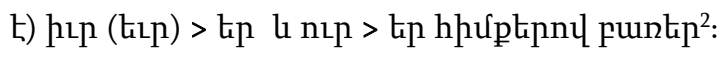

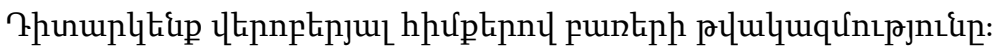

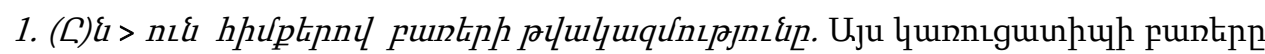

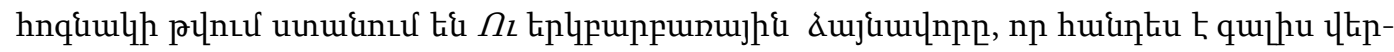

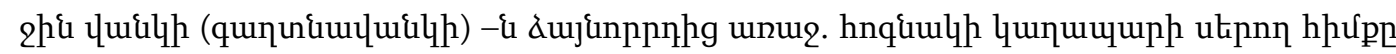

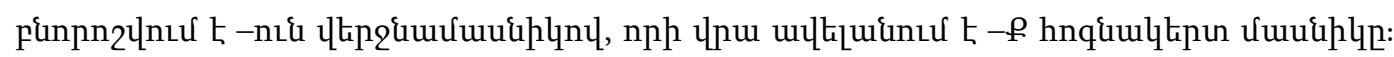

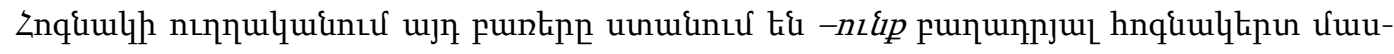
¿pln: Ujuutiu’

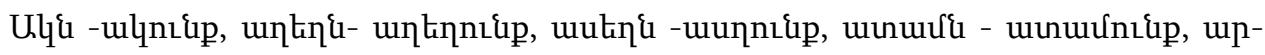

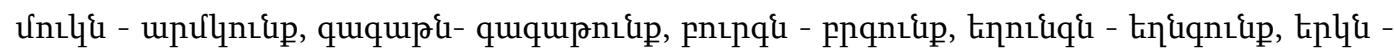

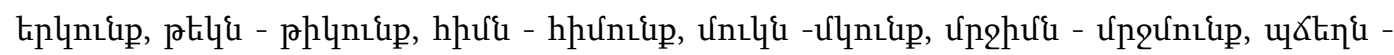

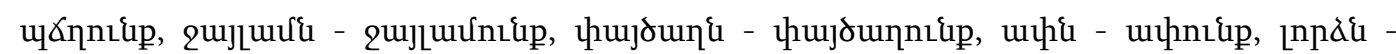

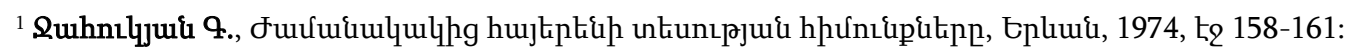

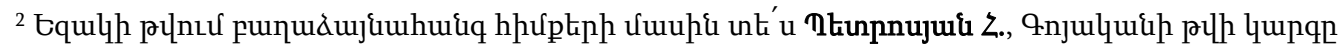
hujtiptínıu, Epluwi, 1972, te 125-126:
} 


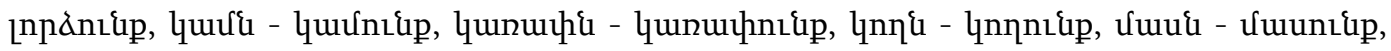

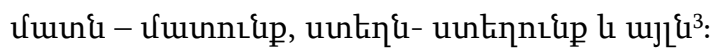

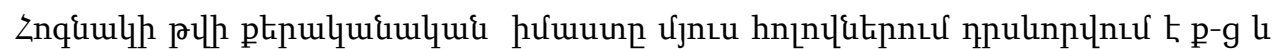

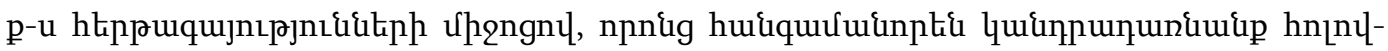

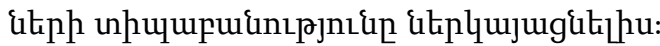

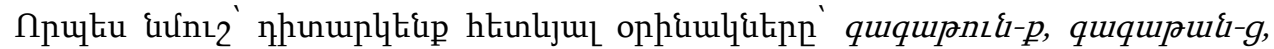

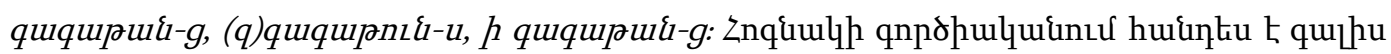

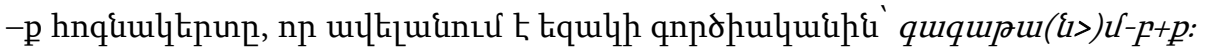

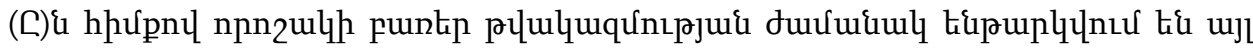

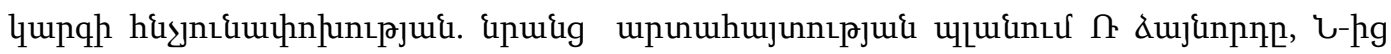

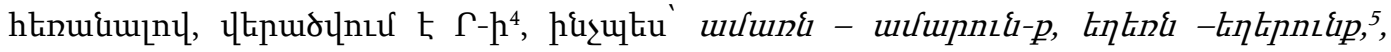

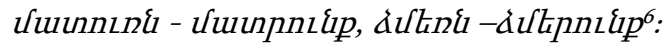

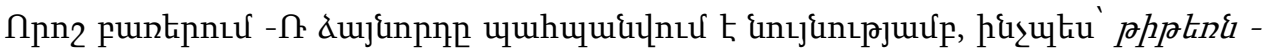

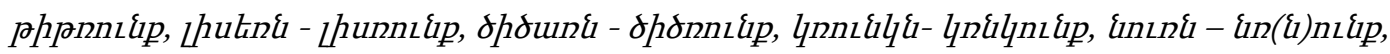

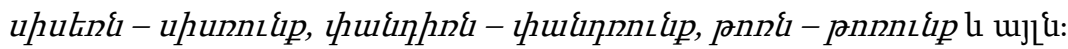

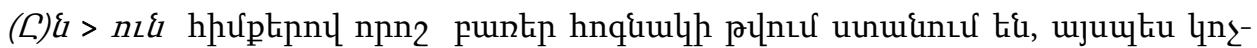

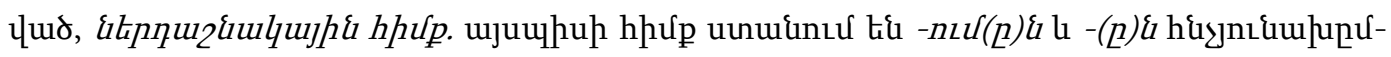

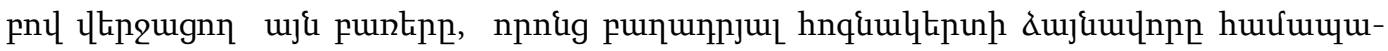

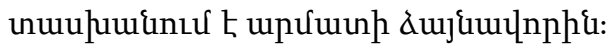

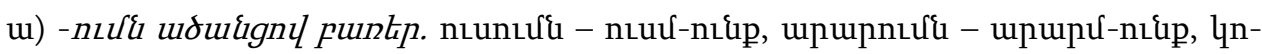

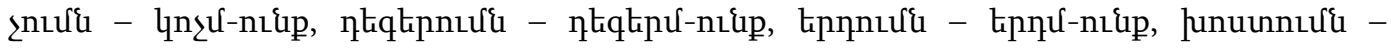

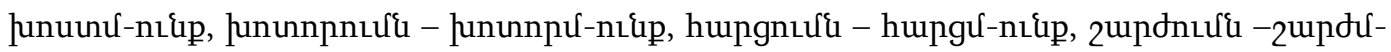
nılip la uృ $\mathrm{u}$,

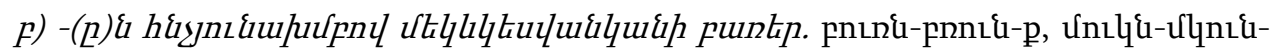

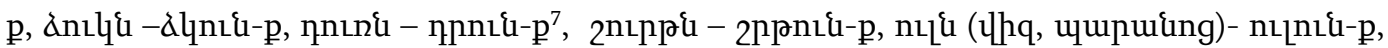

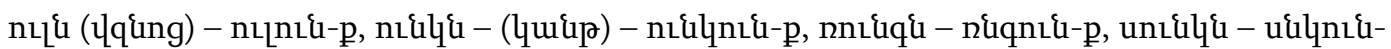

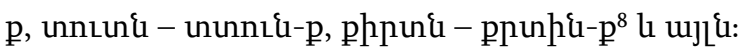

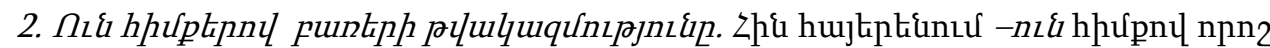

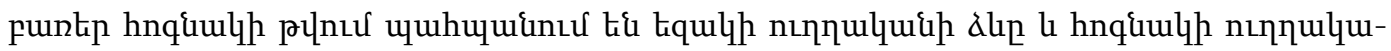

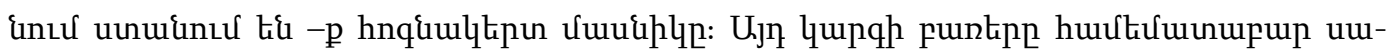

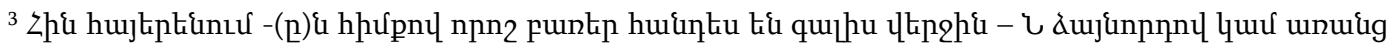

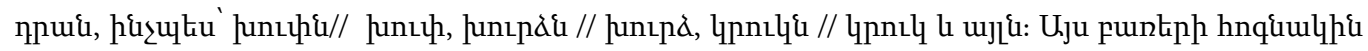

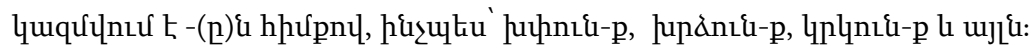

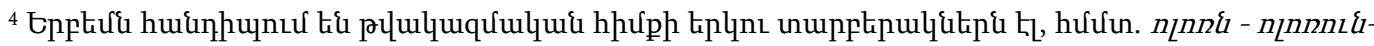
$p / / n$ nnpnLli-p

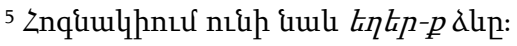

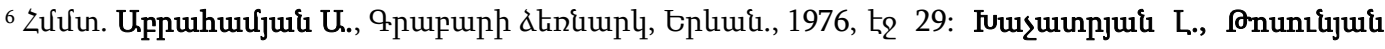

9., 9pupunh quuuqhpp, Epluwid, 2004, to 57:

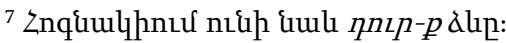

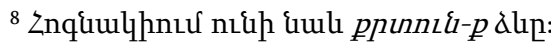




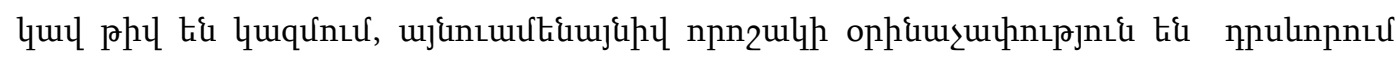

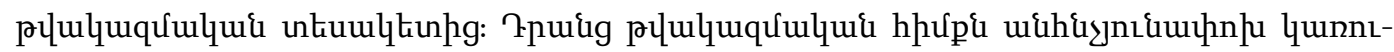

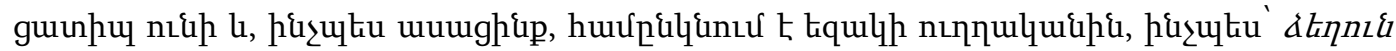

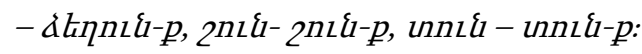

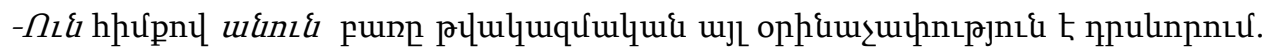

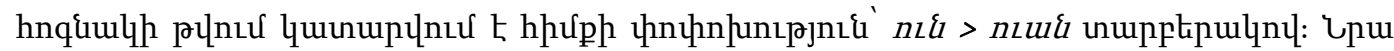

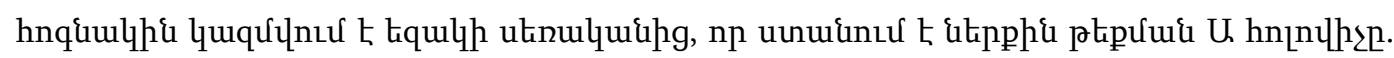

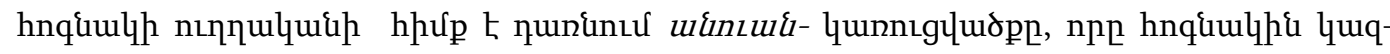

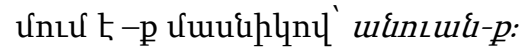

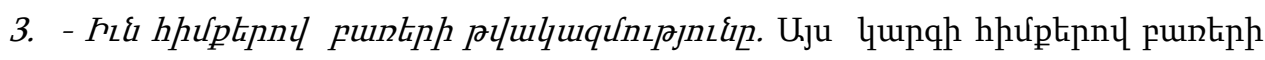

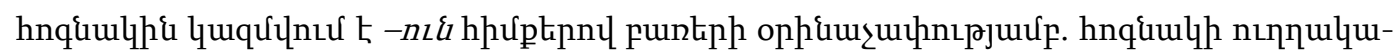

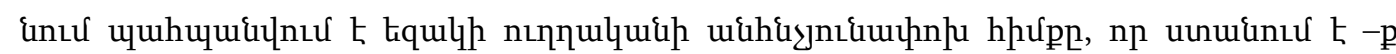

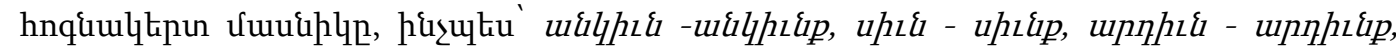

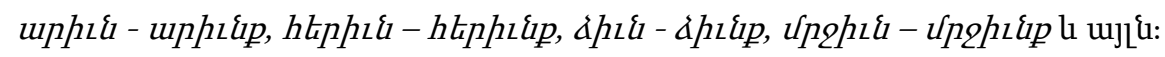

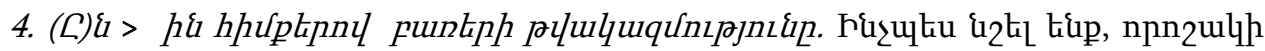

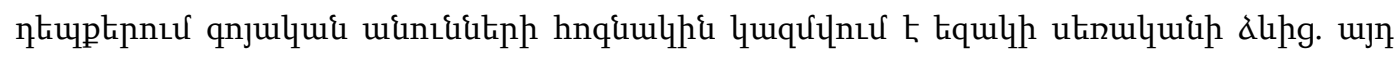

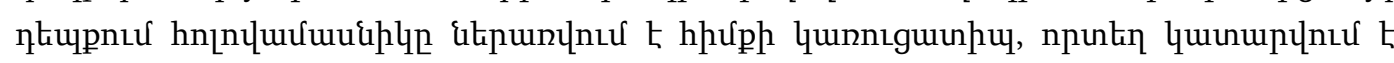

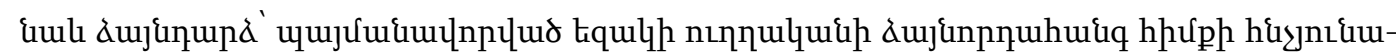

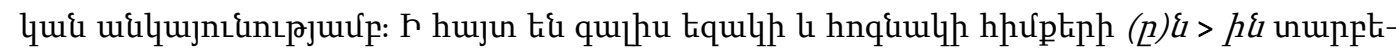
pulqutinn:

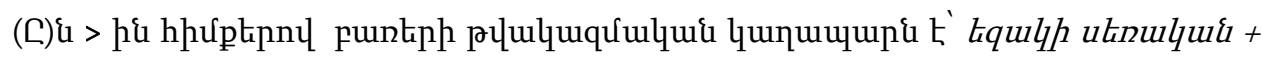

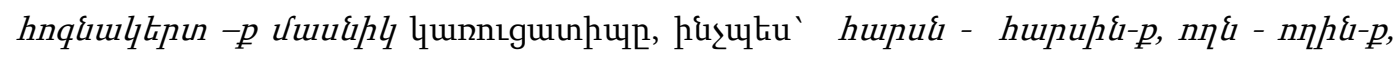

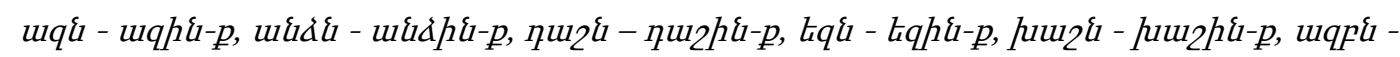

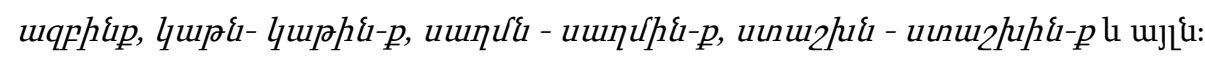

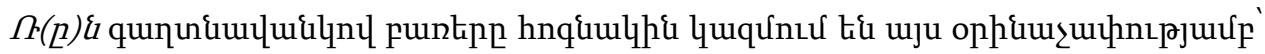

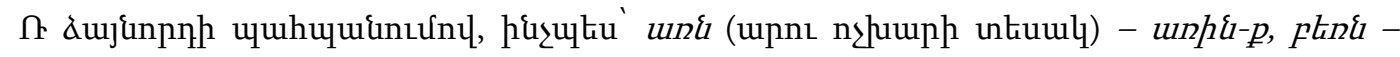

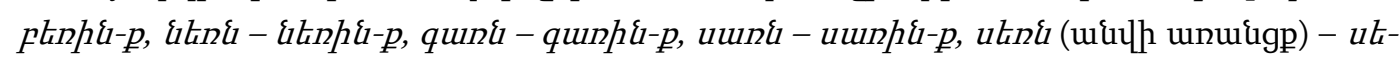
$n h \varepsilon-p$ lu uJL:

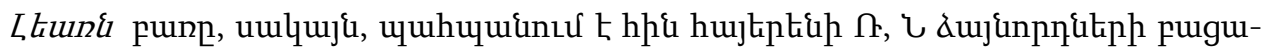

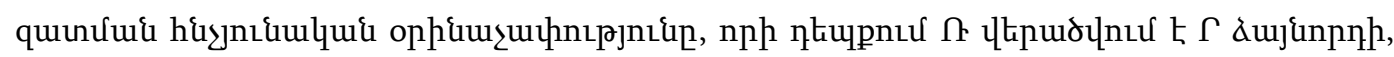
hưưn. Ltuund - ¿thphil-p:

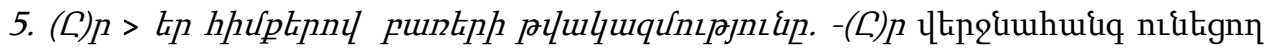

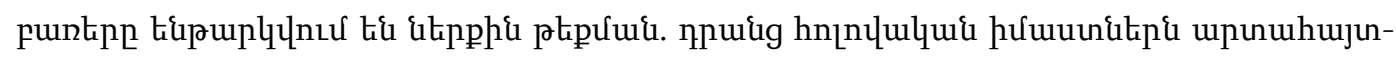

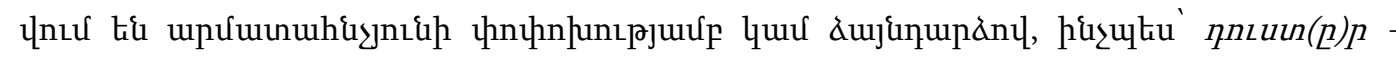

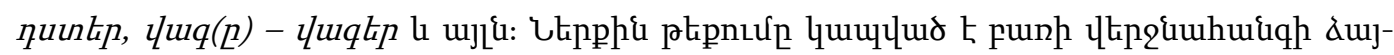

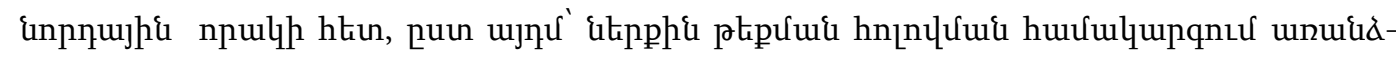

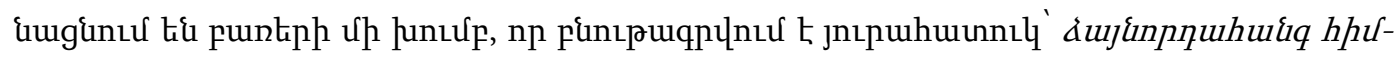

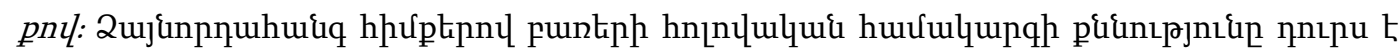

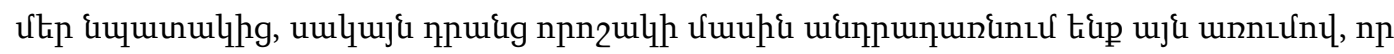

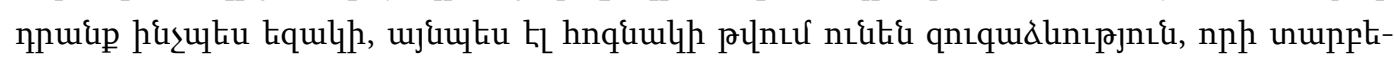




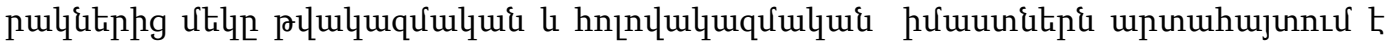

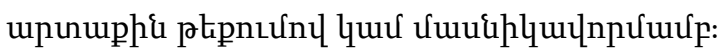

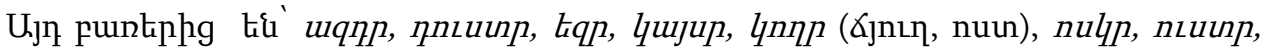

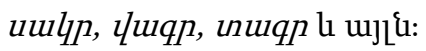

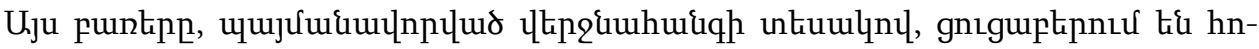

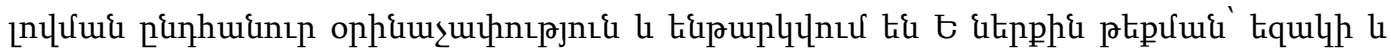
hnquulyh pltipnud:

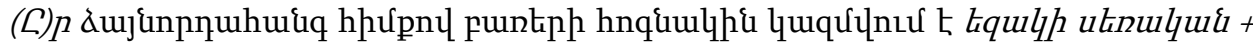

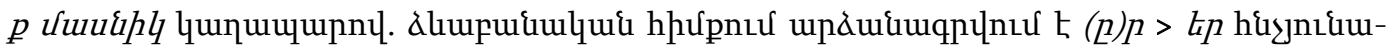

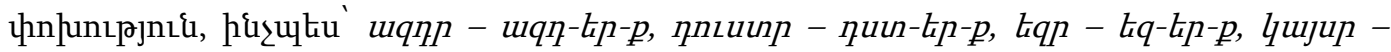

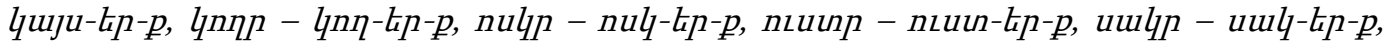

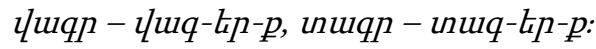

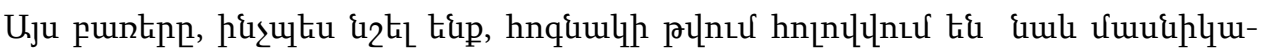

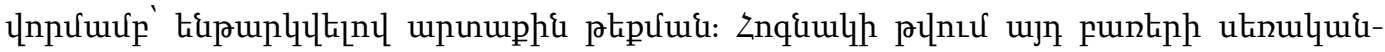

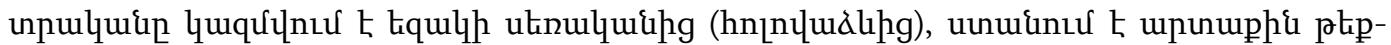

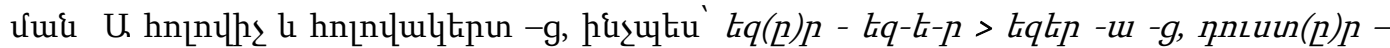

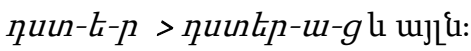

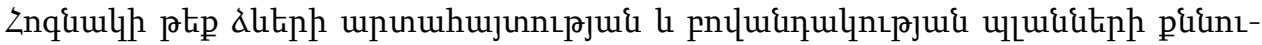

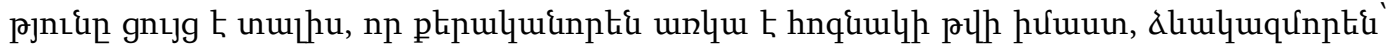

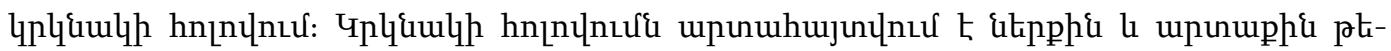

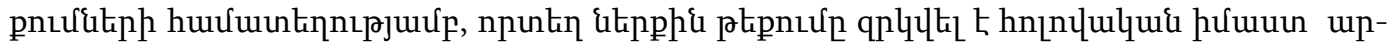

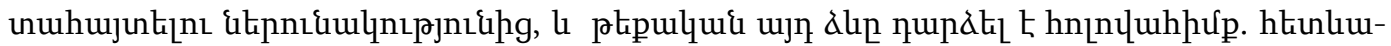

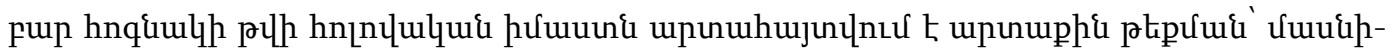

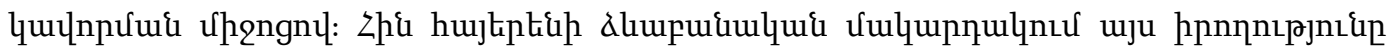

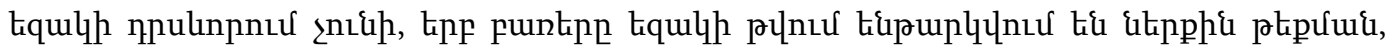

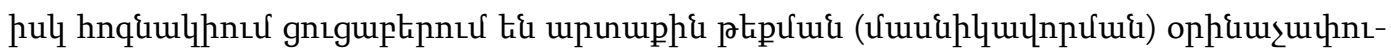
pjni\{:

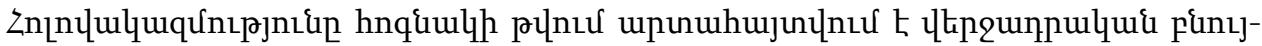

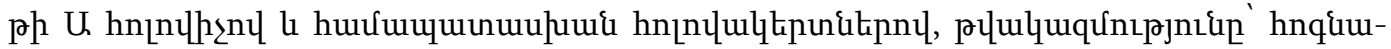

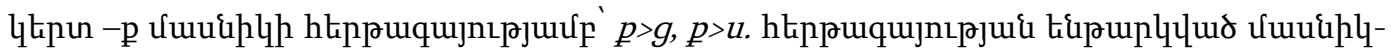

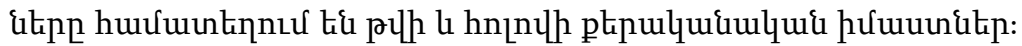

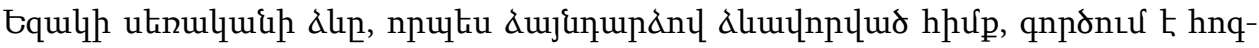

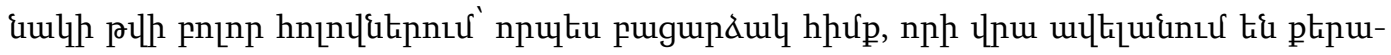

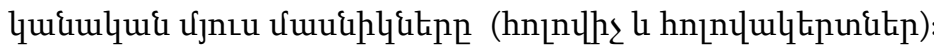

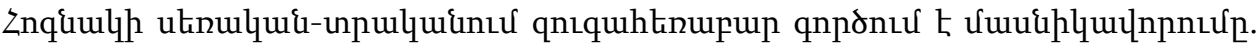

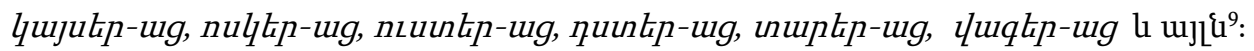

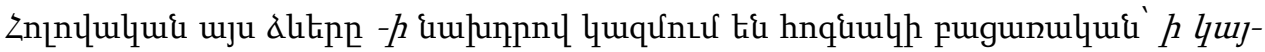

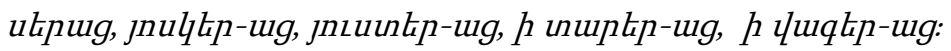

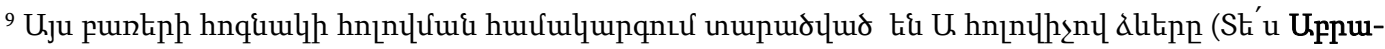

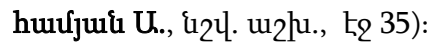




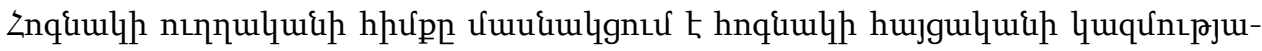

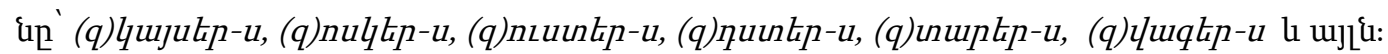

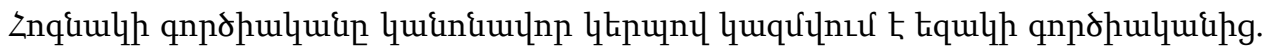

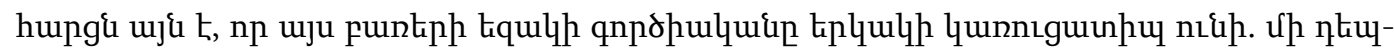

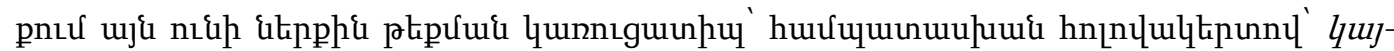

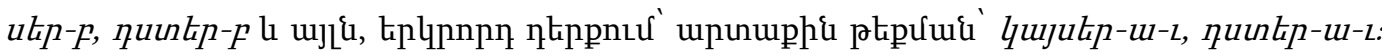

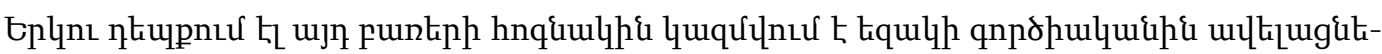

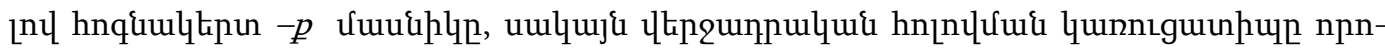

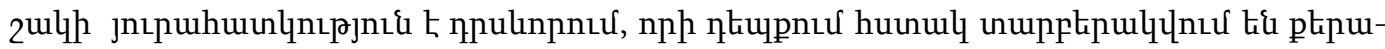

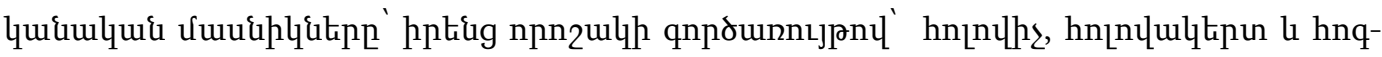

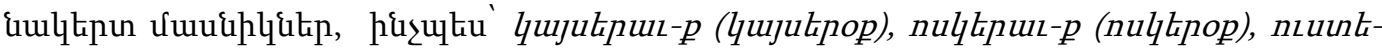

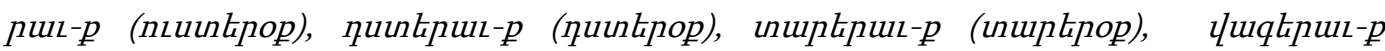
(luqqknop) lu ujL $\mathrm{u}$ :

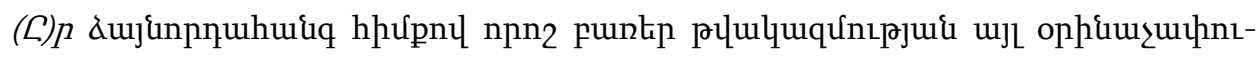
pjnı\& tí gnıguptipnıu:

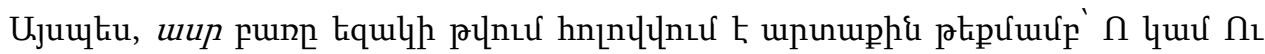

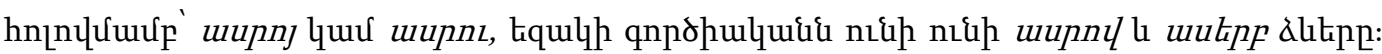

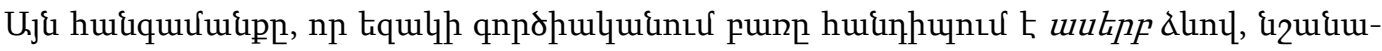

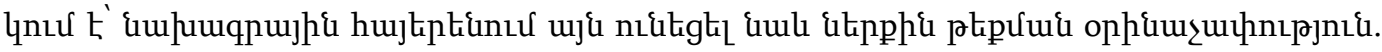

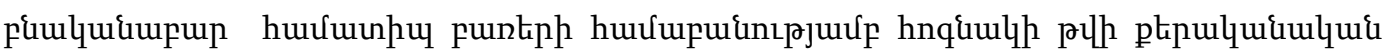

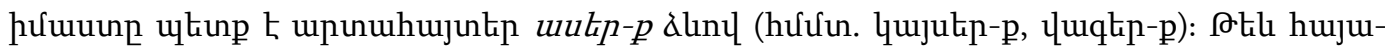

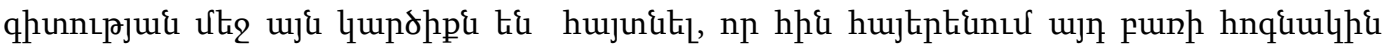

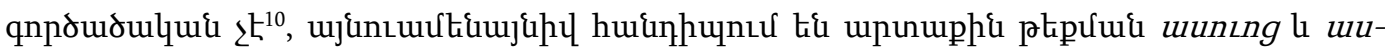

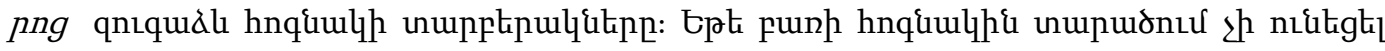

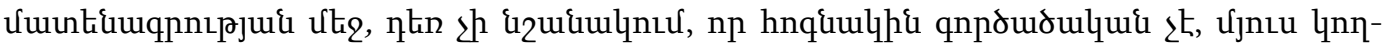

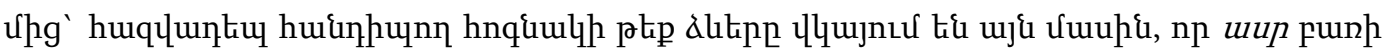

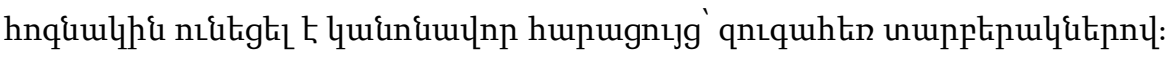

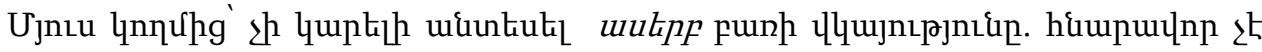

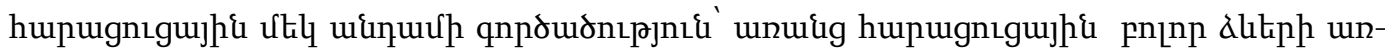

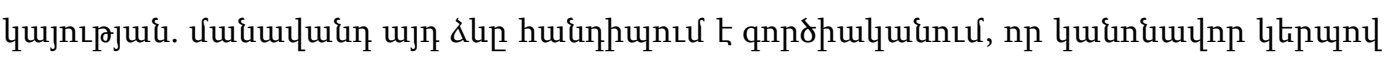

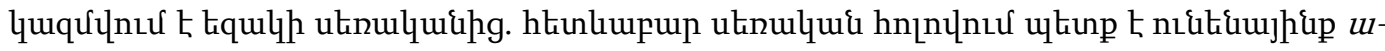

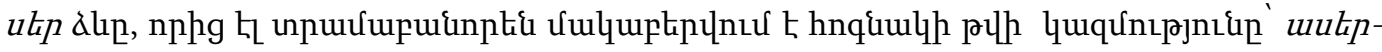

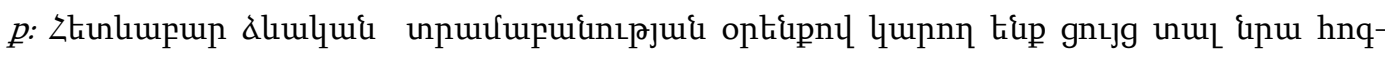

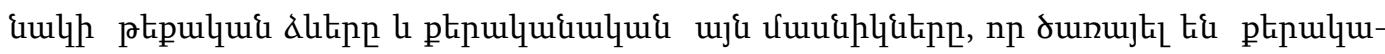

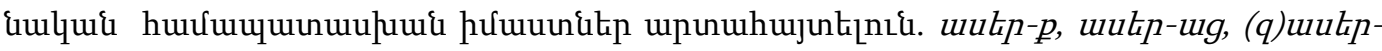

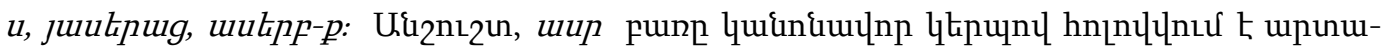

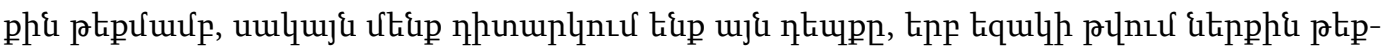

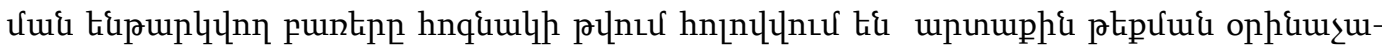

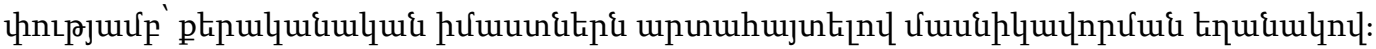

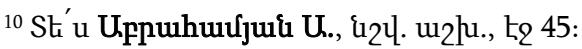




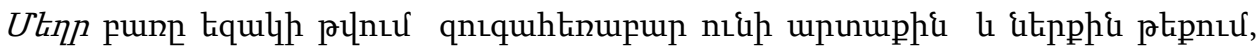

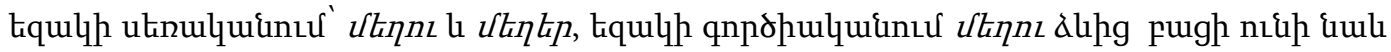

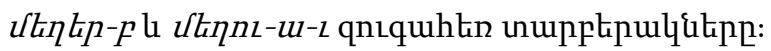

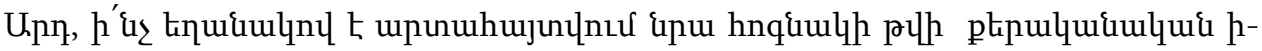

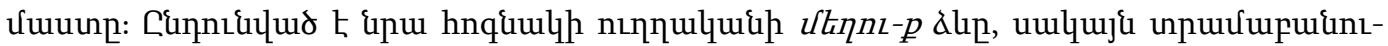

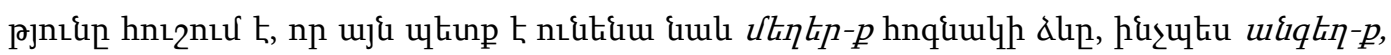

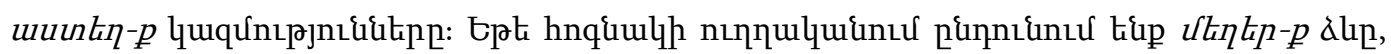

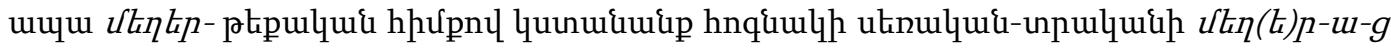

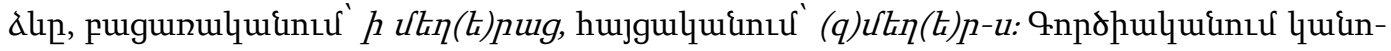

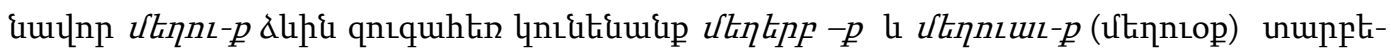

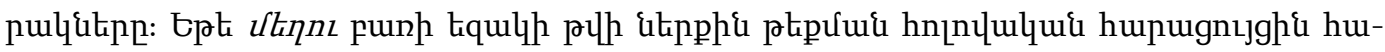

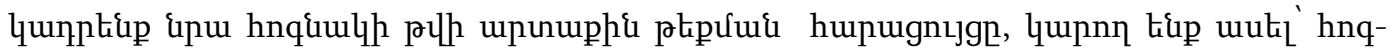

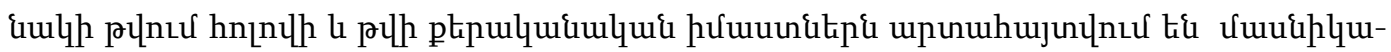

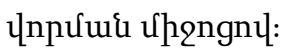

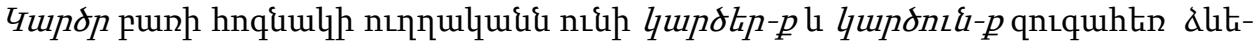

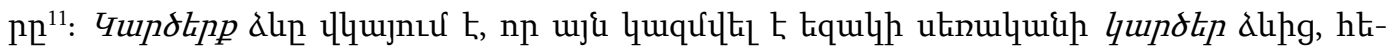

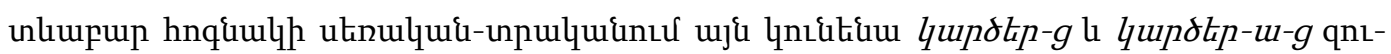

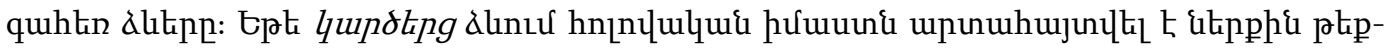

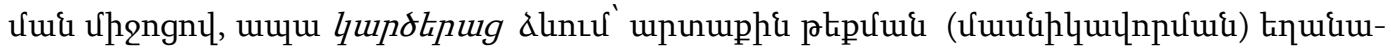

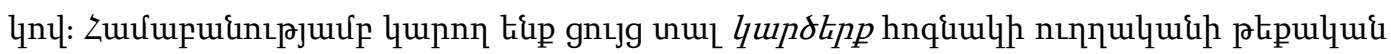

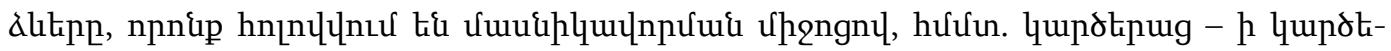

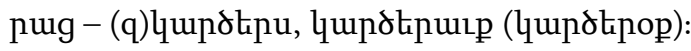

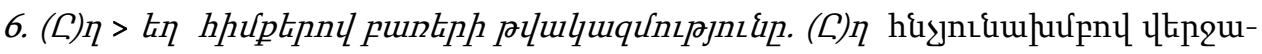

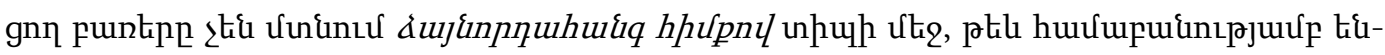

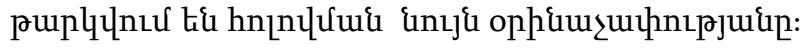

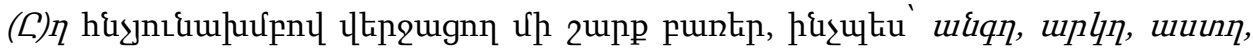

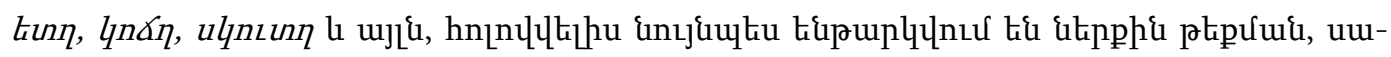

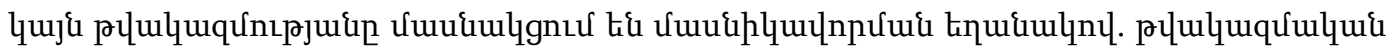

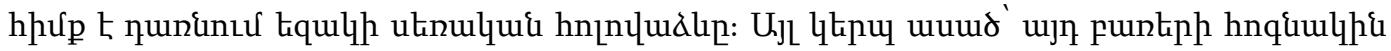
quqư⿱

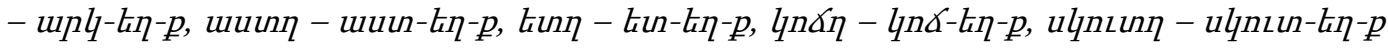

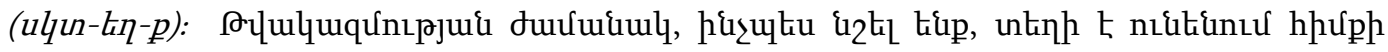

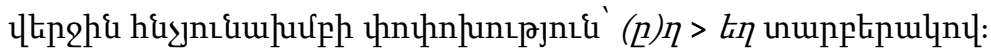

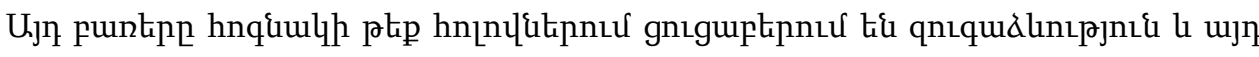

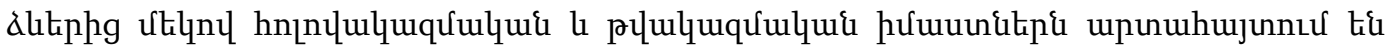

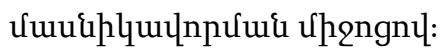

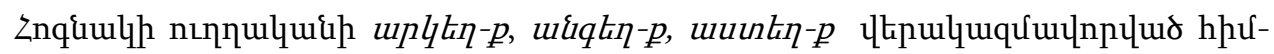

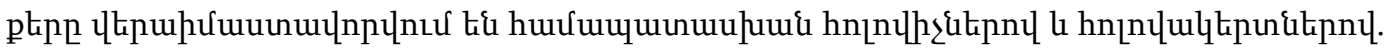

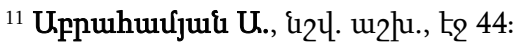




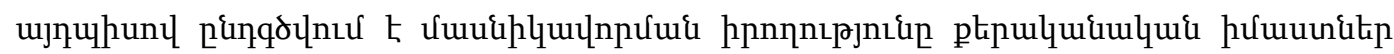
upunuhujuntını unnưnı:

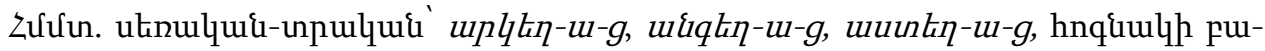

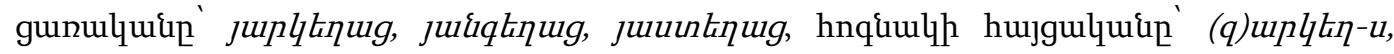

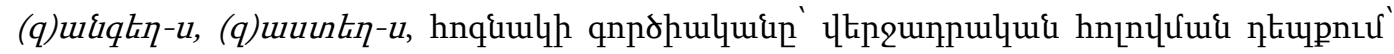

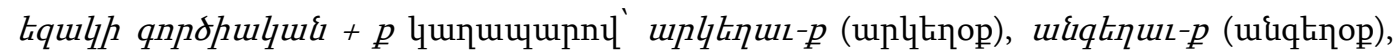

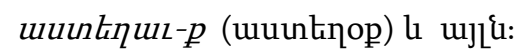

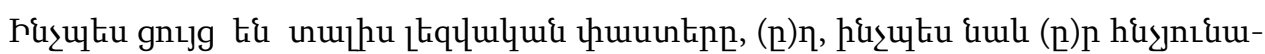

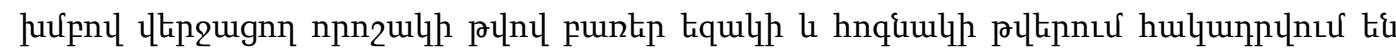

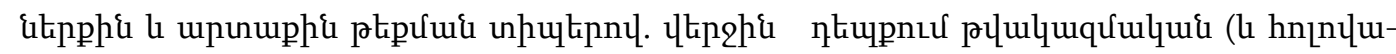

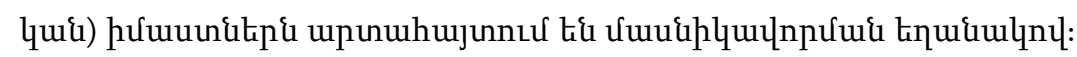

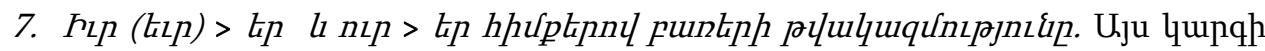

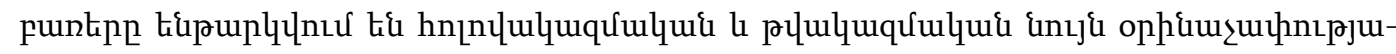

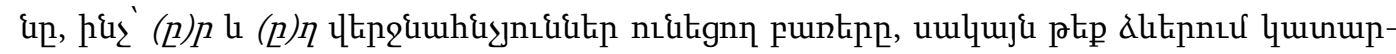

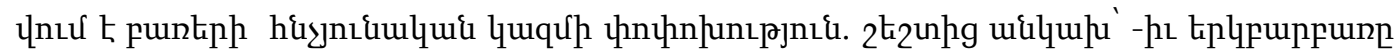

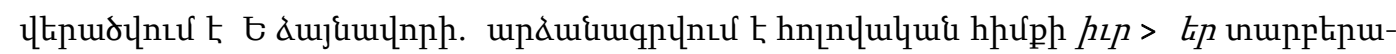

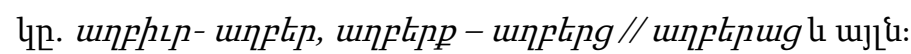

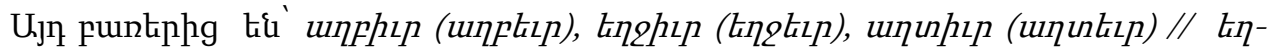

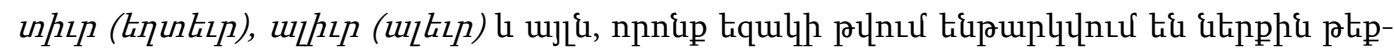

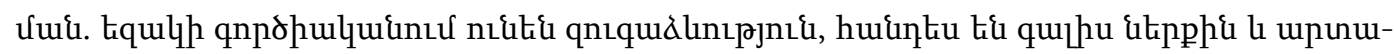

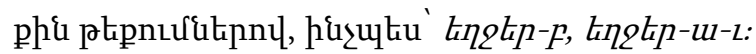

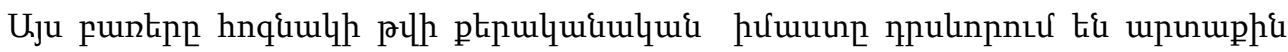

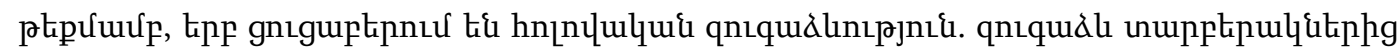

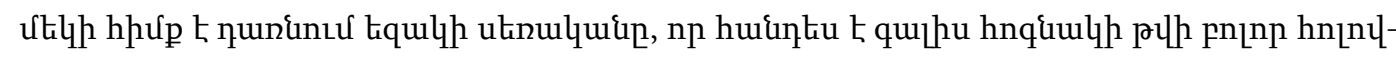
\&iknnux:

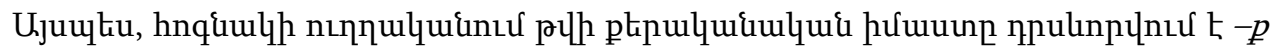

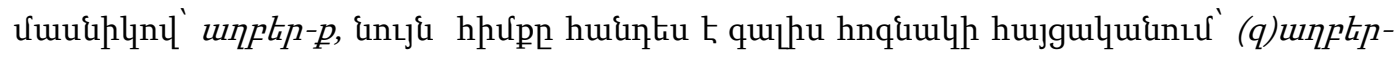

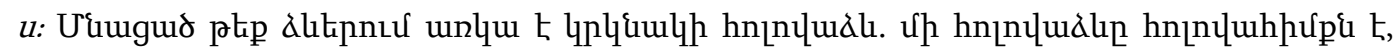

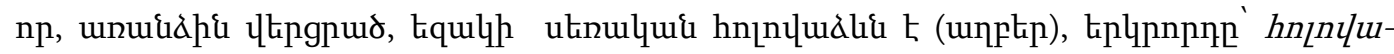

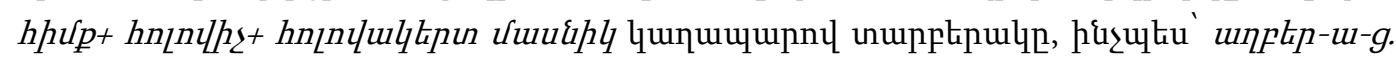

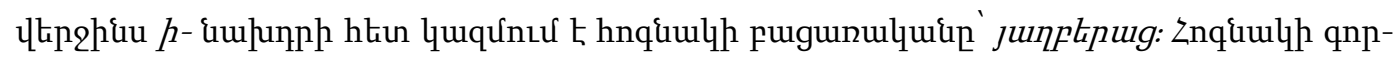

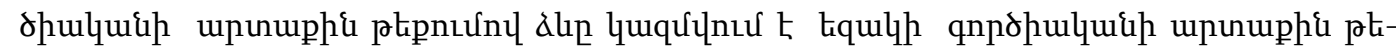

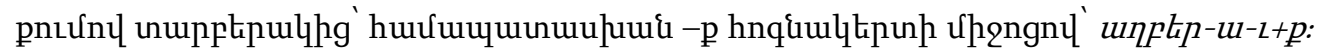

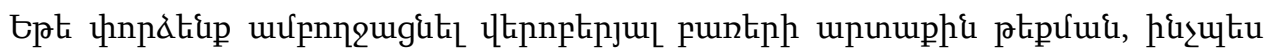

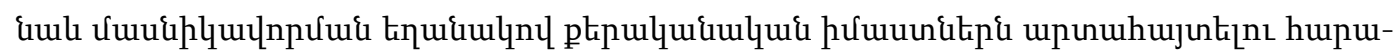

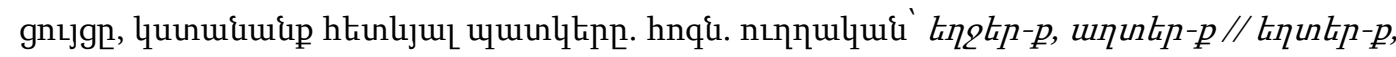

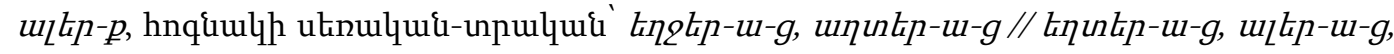

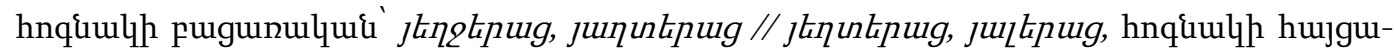

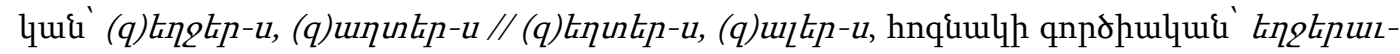

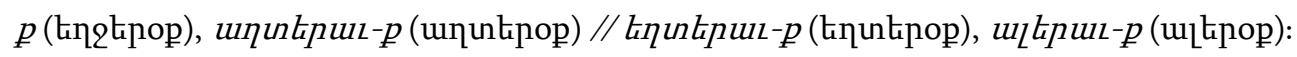




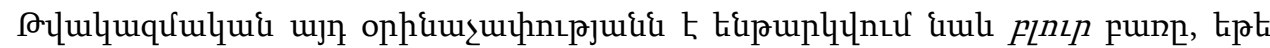

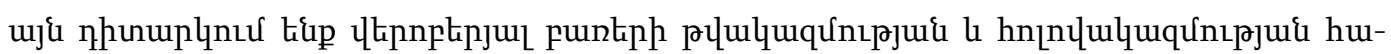

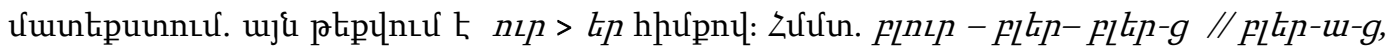

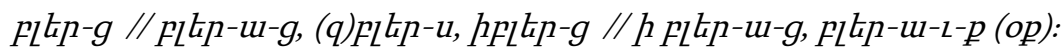

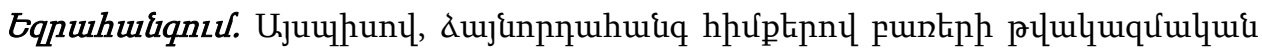

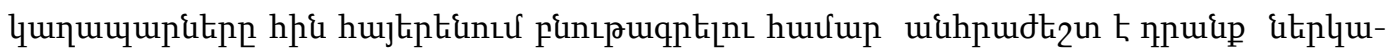

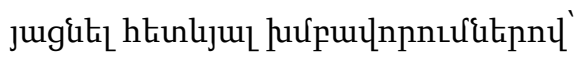

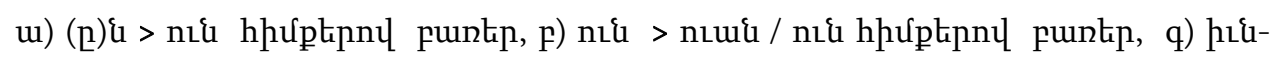

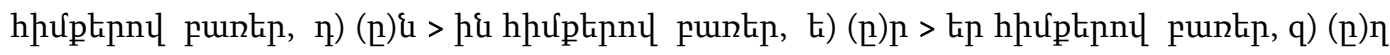

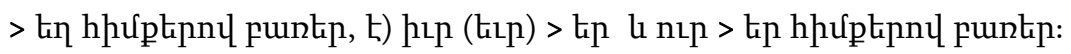

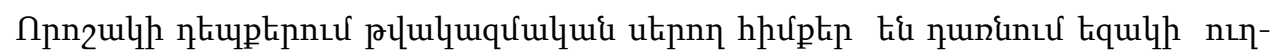

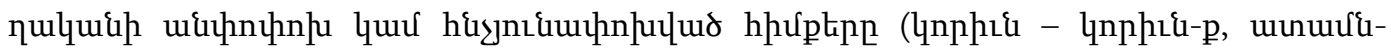

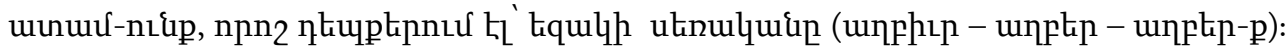

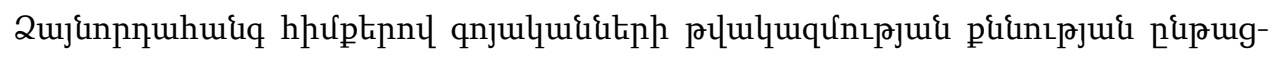

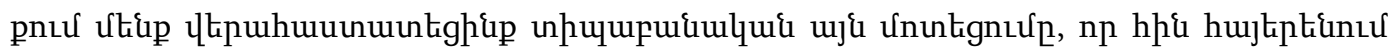

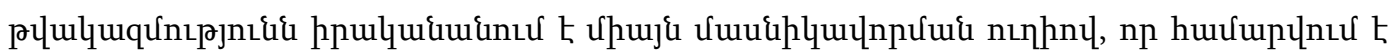

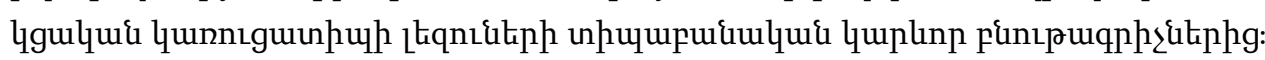

\section{ЧИСЛООБРАЗОВАНИЕ СЛОВ ЗАКАНЧИВАЮЩИХСЯ С СОНАНТАМИ В ДРЕВНЕЯРМЯНСКОМ ЯЗЫКЕ}

\section{Хачатрян Л. Л.}

Ключевые слова: категория числа, множественное число, аффиксация, числообразовательное значение, числообразовательная частища, чередованная основа, нечередованная основа.

Дла характеристики числообразовательных моделей слов заканчивающихся с сонантами необходимо представить эти слова следующими группами;

а) слова с основами ( $\mathrm{L})\{>$ ntq (ququpq- ququpntqp),

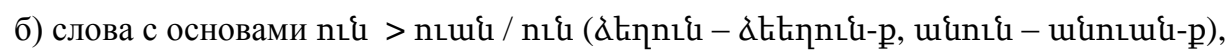

в) слова с основами hı\&- (uqlhı\& - uquhtq-p),

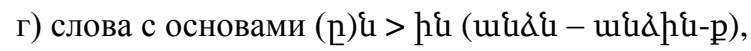

д) слова с основами (p)p > kp ( цuqp - uuqkp-p),

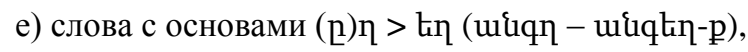

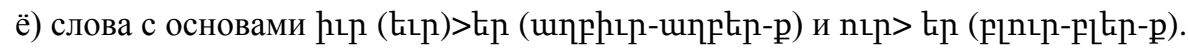

В некоторых случаях неизмененные или чередованные основы единственного чис-

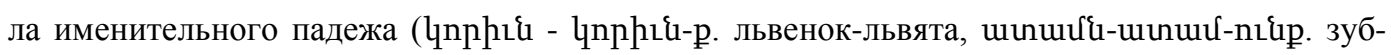
зубы), иногда и родительный падеж в единственном числе (unphlp - unptp - unptp-p. родник-родники) выступают в роли числообразовательных основ.

Анализ числообразования существительных заканчивающихся с сонантами подтверждает тот типологической подход, согласно которому, числообразование в древнеармян- 
ском языке осуществляется с помощью аффиксации. Аффиксация является важным типологическим маркером агглютинативных языков.

\section{THE NUMBER FORMATION OF WORDS ENDING WITH SONANT STEMS IN OLD ARMENIAN. \\ Khachatryan L. L.}

Key words: category of number, plural number, affixation, number-forming meaning, numberforming particle, words ending with sonant stems, stem with sound interchange, stem without sound interchange.

For describing the number-forming patterns of words ending with consonants it is neccesary to indroduce them in following groups;

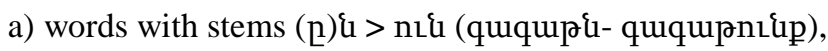

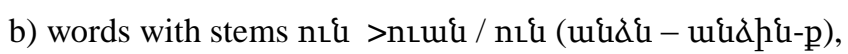

c) words with stems hı\&- (uilhlıq - uquhliq-p),

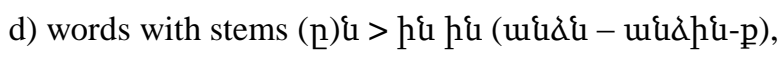

e) words with stems ( $\mathrm{p}) \mathrm{p}>\mathrm{kp}(\mathrm{luqu}-$ luqukn-p),

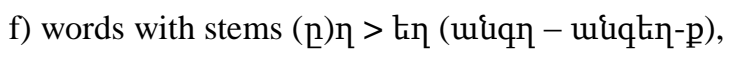

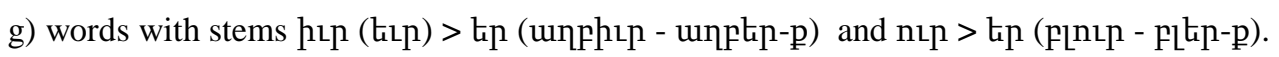

Sometimes plural nominative stems (lnpheq - lnphiqu-p whelp-whelps, uunuuरquunuuf-nLip tooth-teeth) or form of singular possesive ( unphlp - unptip - unptip fountainfountains) with or without sound interchange become number-forming derivative stems.

The analysis of number formation of nouns ending with consonants certifies the typological approach that number formation is realized by affixation in Old Armenian. Affixation is an important typological marker of agglutinative languages.

\section{Q p u $\mathrm{q}$ u $\{\mathrm{nLpjnL}$}

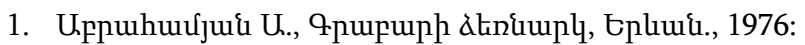

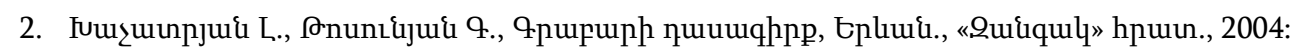

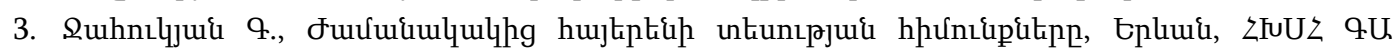
hpuun.,1974;

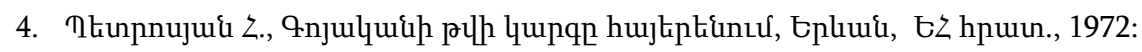

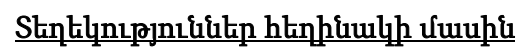

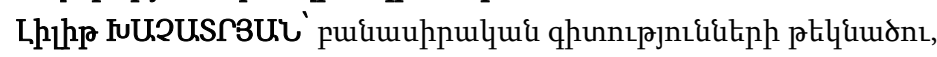

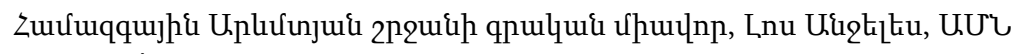

ŁŁuugt’ lilitellen@yahoo.com 